emphasized. Expansion of the East African Metrological Department is planned and promising results were obtained in work on the reduction of evaporation of water from reservoirs with a film of cetyl alcohol.

The Desert Locust Survey maintained close co-operation with the Anti-Locust Research Centre and extra officers were recruited to deal with the re-invasion of the Somali Peninsula. Promising results were obtained in initial field aerial spraying tests with diazinon, and aerodel (11 per cent gamma. BHC) proved ideally suited for spraying locusts even in bad weather over difficult terrain. By the time the locusts started to breed in October 1957 the Survey had concentrated 30 officers and 125 vehicles in the Somaliland Protectorate and eastern Ethiopia and provided 65 vehicles in Somali with adequate supplies of bait and insecticides. Concern is expressed at the almost continuous nature of the threat since the War, but reference is also made to the development of international co-operation under the Food and Agriculture Organization of the United Nations and elsewhere.

\title{
SOIL ZOOLOGY
}

\begin{abstract}
A COLLOQUIUM on "Research Methods in Soil Zoology", organized by the Soil Zoology Committee of the International Society of Soil Science, was held at Rothamsted Experimental Station during July 10-14, by permission of the director (Sir William Ogg) and the director of the Department of Entomology (Dr. K. Mellanby) and with financial assistance from Unesco and the Shell Petroleum Co., Ltd.

Although the titles of the 95 papers give an impression of great diversity, it is possible to distinguish certain themes which emerged from the papers and from the discussions and which are worth reporting to a wider public. This is so largely because the papers, grouped into five sections, were made available to members beforehand and (with a few exceptions) were not read at the conference ; instead, the section recorders provided reviews of the papers, and these were then followed by really useful discussions, during which a reasonable amount of time was available for consideration of the most worthwhile topics.

Perhaps the most constantly recurrent theme was one which belongs most appropriately to Rothamsted, namely, the nature of the relationship between the biologist and the mathematician; this was introduced in the first section on "Methods of Sampling and Analysis". As J. G. Skellam pointed out, the relationships between the structures of the two subjects are indirect, and it is not always appreciated that it is the biologist and not the mathematician who must provide the working hypotheses that are to be tested by the application, for example, of statistical methods to his data. If the biologist simply provides a mass of undigested figures the mathematician is scarcely to be blamed if he erects his system of tests on a mathematically convenient but biologically unrealistic set of hypotheses. This theme was amply illustrated by speakers on such diverse topics as the spatial distribution of soil fauna, the analysis of species composition of communities and the measurement of efficiency of extraction methods.
\end{abstract}

A variant of this theme, on which the views of speakers proved irreconcilable, was the roles of experiment and statistical analysis in biological science. Whereas Dr. K. Mellanby and Prof. Kühnelt (Vienna) were advocates of the elegant laboratory experiment resulting in the production of few, but reliable, data and the support of field work wherever possible by laboratory experiment, Dr. J. E. Satchell (Merlewood) and others were strongly in favour of the use of mathematical analysis on selected field data, and Prof. M. Ghilarov (Moscow) and Prof. Franz (Vienna) were of the opinion that such methods are usually inappropriate owing to imperfect sampling methods and patchy distribution of soil organisms. Although there must obviously be room for great differences in approach to so wide a field, it was evident that the use of statistic:s as an analytical tool is still rather limited outside the English-and French-speaking countries and that the need for the kind of work that we associate with the name of Rothamsted is still great.

A most useful contribution to this liaison work was the first paper by M. J. R. Healy, whose survey of basic statistical techniques concluded with sections on non-random distributions and the use of transformations in variance analysis. Prof. H. R. Debauche (Louvain) as recorder of this section reviewed a wide range of topics in which mathematical techniques are appropriate to ecological studies, including, especially, the analysis of production and energy flow and the delimitation of communities. J. G. Skellam introduced a mathematical analysis of the use of extraction methods for population estimation with emphasis on the effect of extraction-rate and population heterogeneity on accuracy. Also from the Nature Conservancy D. D. Mountford introduced a new method for classifying species records into associated groups ; this method was devised for the analysis of records obtained by J. E. Satchell covering between 50 and 100 species at each of ten sites, and is noteworthy, first, because an estimate of statistical significance is provided, and secondly, because this was the first occasion at the Colloquium on which the use of an electronic computer was reported, the distribution data for the species having been fed to the machine at Rothamsted on punch cards. Evidently this is but the beginning of a further field of application for these machines, for the next paper, by Dr. R. E. Blackith (Imperial College of Science and Technology), acknowledged their value in a discussion of the fields of application of multivariate analysis. Further contributions to this section were concerned with the study of distributions of aggregated populations along more or less familiar lines, Dr. R. D. Hughes (Wellesbourne) introducing a novel technique for estimating mean radius and frequency of patches of high density.

The second section, on "Extraction Methods", was reviewed by the recorder, Dr. P. W. Murphy, and was followed by demonstrations of apparatus and techniques. Some of the methods were already familiar, but new features introduced in the twentyfour papers or in the discussion included an extension of the use of suction methods for collecting ground surface arthropods, a machine for brushing microscopic species from leaves, the use of marking tech- 
niques both for population estimation and for assessment of the accuracy of extraction methods, the improvement of the extraction efficiency of Tullgren funnel methods by the control of humidity and the use of solar heat for funnels in large-scale faunal survey work in the U.S.S.R. Reports of comparative trials of different methods served to underline the variations in efficiency which occur when the same method is used on different animal groups, on different soil types and even in the hands of different operators.

The third section, on "Systematics and the Ecologist", was summarized by Dr. H. Gisin (president of the Committee), who was especially concerned with the relationships between the ecologist and the taxonomist when co-operating in the study of the more 'difficult' groups such as the mites and the Collembola. The taxonomist has the right to receive material in good condition, to be spared preliminary sorting and to make decisions about publication on taxonomic matters, in exchange for which the ecologist can expect rapid determination of selected material and the provision of keys at least to generic level. When determinations to species are required, a fruitful field of co-operation is provided because large ecological differences may accompany only small variations in morphology. There were differences of opinion about the value of reference collections, at least when these are uncritically used, and about the extent to which keys should be carried to the level of species, and should be limited to single countries or natural faunistic regions. Prof. Franz announced a scheme for the uniform publication of a series of keys to the European soil fauna under his editorship and published in Berlin, and Dr. G. O. Evans (British Museum, Natural History) described another scheme for a European key to genera of mites in collaboration with Dr. J. Balogh (Budapest) and Dr. K. Strenzke (Wilhelmshaven). A number of taxonomists present made pleas for correct mounting and preservation methods (not all of which were compatible) and described suitable techniques.

The fourth section, on "Soil Zoology and Pedology", was introduced by Prof. H. Franz (Vienna), who insisted on the need for close liaison between the two subjects. The influence of the past history of a soil on its present fauna and characteristics and the nature of the distinction between the aquatic and aerial components of the soil fauna were discussed. The papers in this section included two methods for studying the nature and rate of decomposition of the latter.

The fifth section, on "Laboratory Techniques", was ably reviewed by J. d'Aguilar (Versailles) and included twenty-nine papers on three main fields, namely : (1) the study of soil by sectioning, microscopical and photographic techniques; (2) the use of numerous special culture methods for different groups of soil animals ; and (3) methods for studying metabolism of soil animals by means of radioisotopes and of a special micro-respirometer. Further details of techniques were provided in the discussion together with some sobering examples of ways in which unforeseen factors can cause faulty experimental results; in this way the complementary roles of laboratory and field work were vividly illustratedat least to those not too far committed to one or other school.

The value of the colloquium was much enhanced by the efficient organization of the secretaries, Dr. P. W. Murphy (Rothamsted) and J. d'Aguilar (Versailles), and owed much to the wise and sympathetic chairmanship of Dr. Mellanby and his colleagues. The discussions throughout were recorded, and translation was ably supplied between English and German. The proceedings, including the discussions, are to be published this year by Messrs. Butterworths in two volumes, the first covering Sections 1-4, and the second containing the papers in Section 5 which are thought likely to have a wider appeal.

A. Macfadyen

\section{BRITISH COAL UTILIZATION RESEARCH ASSOCIATION}

\begin{abstract}
$\mathrm{T}$ HE annual report* of the British Coal Utilization Research Association for 1957 includes a brief review of the Association's research work. 'The major objectives during the year were to help in bridging the gap between suitable coal supplies and energy requirements and assisting the implementation of the Clean Air Act. The development of a small-pipe system for central heating was substantially completed, as was work on the formulation of procedures and the design of equipment for measuring the emission of grit and dust; an automatic particle counter and sizer developed by the Association is now in commercial production. Tests at Leatherhead on the stationary locomotive boiler were also completed and further experimental work with the model furnace-tube plant has reduced the unaccounted heat loss to about $2-3$ per cent Increased attention is now being given to automatic control of firing appliances and, with the increasing use of small coal in such equipment, to the study of grit and dust catchers.
\end{abstract}

\footnotetext{
* British Coal Utilization Research Association. Annual Report
} Research Association, 1958.) $10 s$.
An improved method was devised for controlling the air distribution through the fuel beds of chain grate stokers for boilers of the shell type, and methods of alleviating the rapid corrosion at the cold end of a boiler, particularly of air heater surfaces, have also been investigated.

Laboratory studies continued on the mode of release of chlorine, alkalis and sulphur from coal up to $1,500^{\circ}$ under shock heating conditions, and further tests have shown that the potential tar yield of the coal as defined by the Gray King Assay provides a good basis for comparing coals for tar content. Problems associated with the production of fuel or synthetic gas in gasifiers operating at high pressures and temperatures, at which the ash is in the form of liquid slag, were also investigated with the view of utilizing small low-rank coal.

Basic research included investigations into the chemical basis of the plastic softening of coals, with the view of better control of coking properties ; studies of the fundamental reactivity of graphite towards oxidizing gases in relation to porous structure; and on the solvent extraction of a medium-rank coal with 